\title{
Prophylactic Laparoscopic Total Gastrectomy with Jejunal Pouch Reconstruction in Patients Carrying a CDH1 Germline Mutation
}

\author{
L. Haverkamp ${ }^{1}$ - P.C. van der Sluis ${ }^{1}$ - M.G.E.M. Ausems ${ }^{2}$ - S. van der Horst ${ }^{1}$ • \\ P.D. Siersema ${ }^{3}$ - J.P. Ruurda ${ }^{1}$ - G.J.A. Offerhaus ${ }^{4} \cdot$ R. van Hillegersberg ${ }^{1}$
}

Received: 2 June 2015 / Accepted: 17 September 2015 / Published online: 6 October 2015

(C) 2015 The Author(s). This article is published with open access at Springerlink.com

\begin{abstract}
Background For patients with an identified germline E-cadherin-1 (CDH1) mutation, prophylactic gastrectomy is the treatment of choice to eliminate the high risk of developing diffuse gastric cancer. Laparoscopic total gastrectomy with jejunal pouch reconstruction is a novel approach that may be especially suitable in these patients.

Methods Patients with a germline CDH1 mutation who underwent prophylactic laparoscopic total gastrectomy with jejunal pouch were included in our prospective database.

Results A total of 11 patients with a median age of 40 (22-61)years were included. The average operative time was 4:26 $\pm 0: 49 \mathrm{~h}$ and the average blood loss was $219 \pm 155 \mathrm{ml}$. Median length of hospital stay was 10 (7-27)days. In two patients, an esophagojejunal anastomotic leakage occurred (grade 4). The leakages were seen in patient numbers 2 and 3 , which may be a result of a learning curve. The latter eight patients did not develop anastomotic leakage. Pulmonary complications occurred in one patient with atelectasis and in one patient with pneumonia (grade 2). The 60-day mortality rate was $0 \%$. Multiple foci of intramucosal diffuse gastric signet ring cell carcinoma were found in the resection specimen of 9/11 (82\%) patients. All 11/11 $(100 \%)$ resections were microscopically radical.

Conclusions Prophylactic laparoscopic total gastrectomy with jejunal pouch reconstruction in patients with a CDH1 germline mutation is feasible and safe. In $82 \%$ of patients, foci of intramucosal diffuse gastric signet ring cell carcinoma in the resection specimen were found.
\end{abstract}

Presented at: Consensus conference Hereditary Diffuse Gastric Cancer, March 19th-21st 2014, Nijmegen, the Netherlands.

L. Haverkamp

leonie.haverkamp@gmail.com

R. van Hillegersberg

r.vanhillegersberg@umcutrecht.nl

1 Department of Surgery, University Medical Center Utrecht, Heidelberglaan 100, 3584 CX Utrecht, The Netherlands

2 Department of Medical Genetics, University Medical Center Utrecht, Heidelberglaan 100, 3584 CX Utrecht, The Netherlands

3 Department of Gastroenterology and Hepatology, University Medical Center Utrecht, Heidelberglaan 100, 3584 CX Utrecht, The Netherlands

4 Department of Pathology, University Medical Center Utrecht, Heidelberglaan 100, 3584 CX Utrecht, The Netherlands
Keywords Gastrectomy · Laparoscopy · Prophylactic · E-cadherin · Cancer

\section{Introduction}

The estimated number of newly diagnosed gastric cancer patients is 989,600 worldwide, accounting for 738,000 cancerrelated deaths. ${ }^{1}$ This number counts for $10 \%$ of all cancerrelated deaths, ranking gastric cancer the second highest cause of cancer death. ${ }^{1}$

Hereditary diffuse gastric cancer represents $1-3 \%$ of all gastric cancers. ${ }^{2}$ In approximately $30 \%$ of families with hereditary diffuse gastric cancer, germline mutations are found in the Ecadherin-1 (CDH1) tumor suppressor gene. ${ }^{3-6}$ The $\mathrm{CDH} 1$ gene codes for the E-cadherin protein, and loss of function of the $\mathrm{CDH} 1$ gene leads to diffuse gastric cancer. Patients who carry CDH1 germline mutations have a lifetime risk of $>70 \%$ of 
developing diffuse gastric cancer with a 5-year survival of less than $20 \%{ }^{7,8}$ Female carriers also have an increased risk to develop lobular breast cancer. ${ }^{9-11}$ Surgery eliminates the high risk of developing diffuse gastric cancer in patients with germline CDH1 mutations and therefore is the treatment of choice. Most reports on prophylactic total gastrectomy in literature describe a conventional open surgical approach. ${ }^{12}$

In gastric cancer, laparoscopic total gastrectomy showed diminished blood loss, fewer postoperative complications, and shorter postoperative hospital stay. ${ }^{13}$ This technique may therefore be especially suitable for prophylactic surgery. In this article, we describe our initial experience with prophylactic laparoscopic total gastrectomy with jejunal pouch in a case series of patients carrying a $\mathrm{CDH} 1$ germline mutation.

\section{Materials and Methods}

\section{Patients}

Patients $(n=11)$ with identified germline CDH1 mutations who were referred to the University Medical Centre Utrecht for prophylactic total gastrectomy between April 2006 and May 2015 were included in this study. All patients were presented and discussed in a multidisciplinary team meeting comprising oncologic surgeons, medical oncologists, gastroenterologist, clinical geneticist, radiologists, and nutritionist prior to treatment. Patient information was recorded into a prospectively maintained database and included demographics, preoperative clinical work-up, surgical results and postoperative complications, pathological results, length of hospital stay, and follow-up. No routine upper gastrointestinal contrast studies were performed to detect anastomotic leakage, instead radiological diagnosis was performed when clinical signs of leakage were present. Complications were scored with the modified Clavien-Dindo classification. ${ }^{14}$

\section{Surgery}

All patients underwent prophylactic laparoscopic total gastrectomy by surgeons experienced in laparoscopic techniques (RvH and JPR). All patients received an epidural catheter to provide adequate postoperative analgesia. Prophylactic antibiotics were administered pre-operatively. After an open introduction of a first trocar in the left hypogastrium, pneumoperitoneum was created and the abdominal cavity was inspected, and two 5-mm trocars were introduced subcostally on both sides and two 12-mm trocars in the right hypogastrium and the right flank under direct sight (Fig. 1). The lesser sac was opened and transected closely to the liver. The left crus of the diaphragm was exposed. Hereafter, the greater gastric curvature was dissected using a harmonic scalpel (Ethicon Endosurgery, Southington, CT, USA) followed by dissection

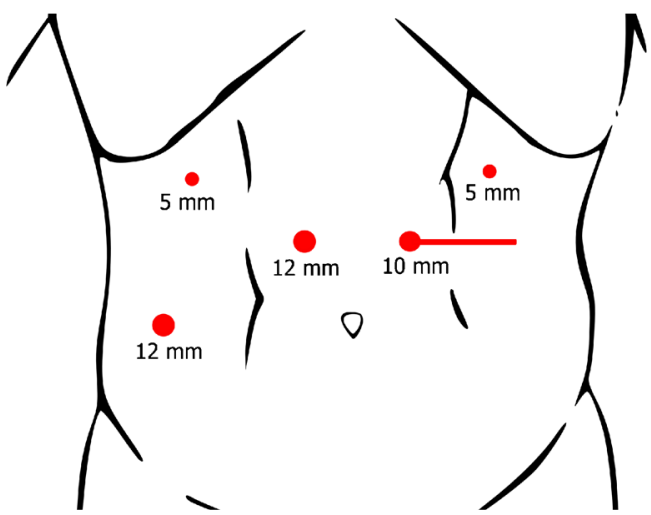

Fig. 1 Trocar arrangement during prophylactic laparoscopic total gastrectomy. The camera was inserted through the $10-\mathrm{mm}$ paraumbilical trocar port and two 5-mm trocars were used as laparoscopic working ports. The liver retractor was inserted through the $12-\mathrm{mm}$ right para-rectal trocar port. The harmonic scalpel was inserted through the 12$\mathrm{mm}$ para-umbilical port. The horizontal line represents the incision that is used to take out the stomach

and ligation of the left gastric artery and vein. The right gastroepiploic artery and vein were dissected and ligated at the level of the duodenum. The duodenum was divided postpyloric with an Endo-GIA stapler (Covidien, Norwalk, CT, USA). The esophagus was mobilized, and a supporting suture was placed on both sides followed by transection of the distal esophagus with an Endo-GIA stapler (Fig. 2). An Orvil stapler (Covidien, Norwalk, CT, USA) anchor was introduced through the oral cavity into the esophagus. In the stapled distal esophagus, an opening was created for the Orvil anchor, which was fixed by a laparoscopically placed purse-string suture around the anchor.

A horizontal incision in the left upper abdomen, with sparing of the rectus muscle, was created through the left 12-mm port, and an Endopath Dextrus ${ }^{\mathrm{TM}}$ (Ethicon Endosurgery, Southington, CT, USA) access port was inserted. The resection specimen was removed through this port and was sent in for frozen section evaluation (Fig. 3). The first bowel loop was divided with an Endo-GIA stapler, and the Roux-en-Y reconstruction was completed with an isoperistaltic side-to-side jejunal-jejunal anastomosis manually created with a PDS 3.0 continuous suture. The distal jejunum was used to create a

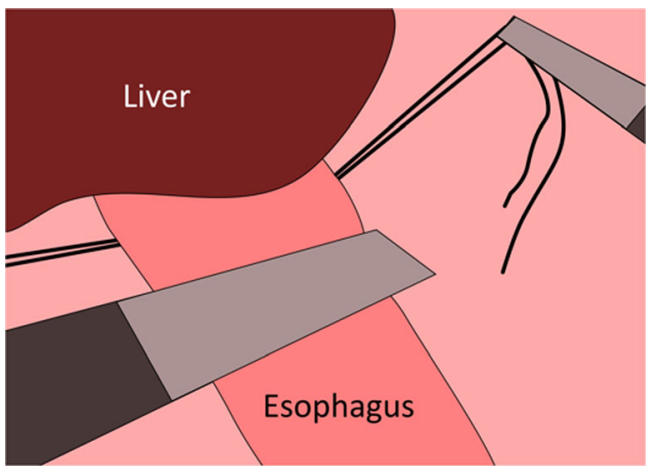

Fig. 2 Placement of a supporting suture on both sides of the esophagus followed by transection of the esophagus by means of an Endo-GIA stapler 


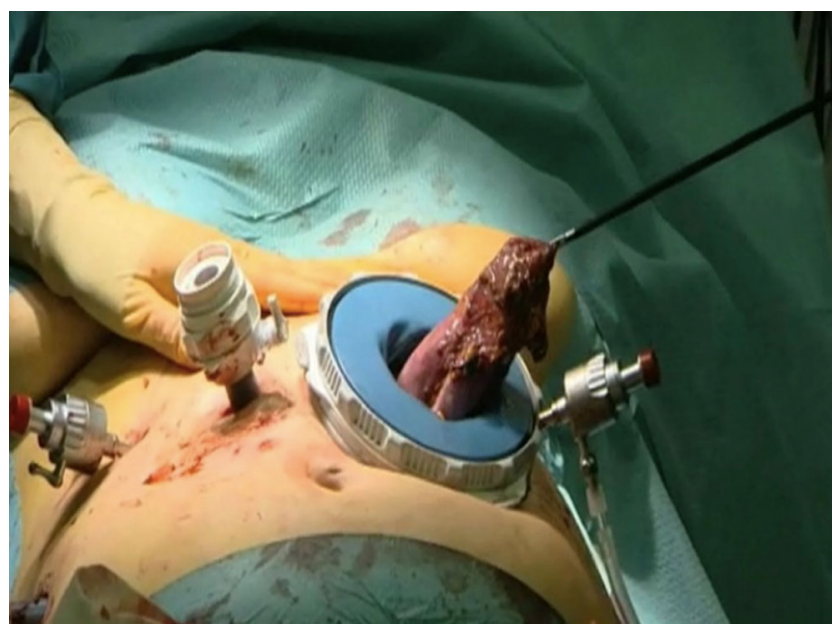

Fig. 3 Removal of the gastric resection specimen through the Endopath Dextrus $^{\mathrm{TM}}$ access port

"J"-shaped pouch (Fig. 4), using a 100-mm linear stapler (Covidien, Norwalk, CT, USA). An antecolic 10-cm esophageal (pouch)-jejunal (EJ) anastomosis was created with the Orvil circular stapler (Fig. 5). The proximal and distal esophageal-jejunal donuts were pathologically examined. The blind jejunal loop was stapled. Distal to this anastomosis, a feeding jejunostomy was inserted.

\section{Pathological Analysis}

The resection specimen was evaluated using a standard protocol, providing information on resection margins and presence of tumor cells. The specimen was completely accessioned; after resection of the proximal and distal margin, the remaining mucosa was cleaved from the underlying deep muscle and fixed overnight according to the so-called Swiss roll technique. ${ }^{15}$ This method consists of isolating a thin strip of gastric mucosa (approximately $4 \mathrm{~mm}$ thick) from the underlying layers and rolling it up in a spiral starting from the distal (duodenal)

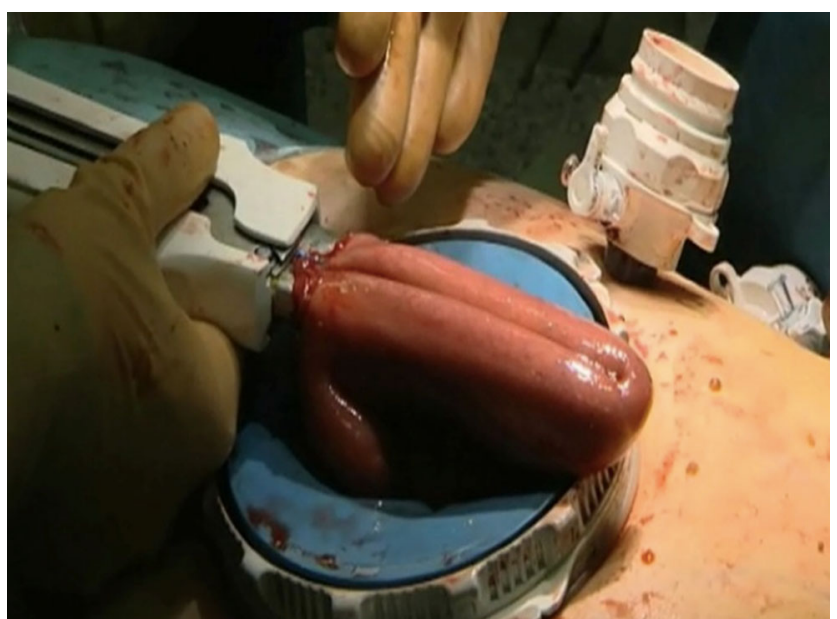

Fig. 4 Creation of a "J"-shaped jejunal pouch, using a 100-mm linear stapler

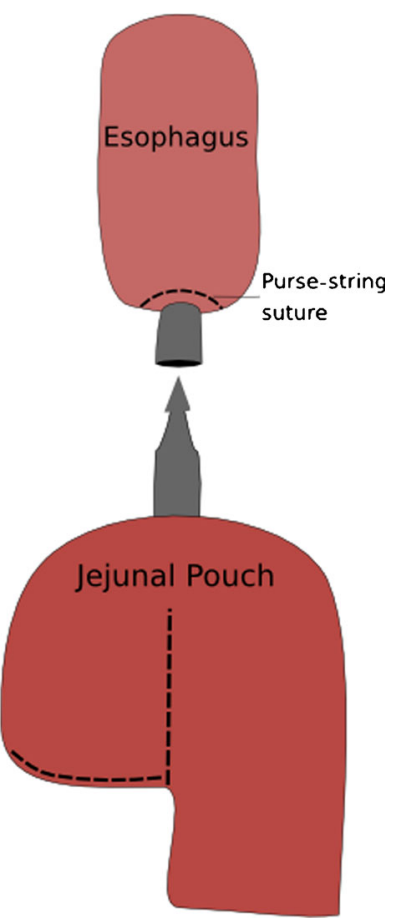

Fig. 5 Creation of an esophagojejunal anastomosis with jejunal pouch with the use of the Orvil circular stapler

margin. This enables complete microscopic investigation of whole gastric mucosa and is particularly suitable when no macroscopic lesions can be recognized. ${ }^{15}$

\section{Results}

A total of 11 patients (eight females, three males) who carried the $\mathrm{CDH} 1$ gene mutation were included and underwent

Table 1 Baseline characteristics

\begin{tabular}{ll}
\hline & $\begin{array}{l}\text { Laparoscopic prophylactic } \\
\text { gastrectomy } \\
N=11\end{array}$ \\
\hline Age $^{\mathrm{a}}$ & $40(22-61)$ \\
Gender (male/female) $^{\mathrm{a}}$ & $3: 8$ \\
BMI $^{\mathrm{a}}$ & $27.8(19.7-35.2)$ \\
Comorbidities & \\
Diabetes mellitus & 0 \\
COPD & 0 \\
Cardiovascular & 1 \\
ASA score & \\
1 & 6 \\
2 & 4 \\
3 & 1 \\
Smoking & 6 \\
Alcohol & 5 \\
\hline
\end{tabular}

${ }^{\mathrm{a}}$ Data presented as median $(\min -\max )$ 
prophylactic laparoscopic total gastrectomy. The median age at the time of surgery of was 40 (22-61)years (Table 1). All patients had an ASA score of 1,2, or 3. The average operative time was 4:26 $\pm 0: 49 \mathrm{~h}$ (Table 2). The average blood loss was $219 \pm 155 \mathrm{ml}$. No blood transfusions were required. One procedure was converted to an open procedure due to an incomplete anastomosis identified during the procedure, which necessitated additional stitches. The median length of postoperative hospital stay was 10 (7-23)days.

In two patients, anastomotic leakage occurred which were treated either by intraoperative anastomotic repair or endoscopic placement of a stent (grades 3-4). Both leakages were detected after surgery. No intraoperative leak test was routinely performed. The first patient was stented due to fistula formation at the level of the anastomosis, and the second patient underwent a re-operation during which an anastomotic dehiscence was seen. This defect was oversewn after which the patient recovered uneventfully. The leakages were seen in patient numbers 2 and 3, which may be a result of a learning curve. The latter eight patients did not develop anastomotic leakage. Minor complications were observed in two patients. One patient suffered from atelectasis and a wound infection, which were treated conservatively (grade 1). One of these patients had a pneumonia, which was treated with intravenous antibiotics (grade 2). The remaining four patients had no early postoperative complications ( $<30$ days postoperatively).

After microscopy of the complete resection specimen, multiple foci of intramucosal diffuse gastric signet ring cell carcinoma or focal intestinal metaplasia were found in the resection specimen of 9/11 (82\%) patients (Fig. 6). The largest focus was $8 \mathrm{~mm}$ in diameter. A median of 10 (1-25) lymph nodes were dissected during laparoscopy, none of which were tumor positive.

Table 2 Intraoperative and postoperative outcomes

\begin{tabular}{ll}
\hline & $\begin{array}{l}\text { Laparoscopic prophylactic } \\
\text { gastrectomy } \\
N=11\end{array}$ \\
\hline${\text { Duration of surgery }(\mathrm{h})^{\mathrm{a}}}^{\mathrm{a}}$ & $4: 26 \pm 0: 49$ \\
Blood loss (ml) $^{\mathrm{a}}$ & $219 \pm 155$ \\
Conversion & 1 \\
Complicated course & 5 \\
Postoperative hospital stay (day) $^{\mathrm{b}}$ & $10(7-23)$ \\
Intensive care stay (day) $^{\mathrm{b}}$ & $0(0-2)$ \\
${\text { Resected lymph nodes }(n)^{\mathrm{b}}}^{\mathrm{b}}$ & $10(1-25)$ \\
R0 resection & 11 \\
Mortality & $0 \%$ \\
30-day mortality & $0 \%$ \\
60-day mortality & \\
\hline
\end{tabular}

${ }^{\text {a }}$ Average \pm standard deviation

${ }^{\mathrm{b}}$ Median (min-max)

\section{Discussion}

In this article, we report our initial experience with prophylactic laparoscopic total gastrectomy with jejunal pouch in patients with a CDH1 germline mutation. In 9/11 (82\%) patients, multiple foci of intramucosal diffuse gastric signet ring cell carcinoma were found in the resection specimens. The laparoscopic technique was shown to be feasible and safe with an average blood loss of $219 \pm 155 \mathrm{ml}$ and median length of hospital stay of 10 days. Postoperative complications occurred in 6/11 (55 \%) patients, and the 60 -day hospital mortality rate was $0 \%$.

Our prophylactic gastrectomy resection specimens were microscopically analyzed using the "Swiss roll" technique. In this fashion, the complete gastric mucosa could be scrutinized by expert pathologists. ${ }^{15}$ In our cohort, multiple foci of intramucosal gastric cancer were found in the resection specimens in $82 \%$ of patients. This is in concordance with other series, where the presence of one or more foci of signet ring cell carcinoma was reported in up to $92 \%$ of all prophylactic gastrectomy pathologic resection specimens. ${ }^{3,16,17}$ The high percentage of intramucosal gastric cancer in both our series and the series from literature emphasizes the need for prophylactic gastrectomy for patients with germline $\mathrm{CDH} 1$ mutations.

In a meta-analysis, we demonstrated that laparoscopic total gastrectomy is associated with reduced intraoperative blood loss, lower risk at postoperative complications, and shorter hospital stay compared to open total gastrectomy in patients with gastric cancer. ${ }^{13}$ These benefits are especially relevant for patients with a $\mathrm{CDH} 1$ germline mutation. Our initial experience with the prophylactic laparoscopic total gastrectomy is promising. We expect that the outcomes of prophylactic laparoscopic total gastrectomy will approximate the results for laparoscopic total gastrectomy for gastric cancer in larger series of patients with a $\mathrm{CDH} 1$ germline mutation.

The median length of hospital stay in our cohort was 10 days. This is higher than reported in a case report of patients that had prophylactic laparoscopic total gastrectomy (median length of hospital stay was 5 days). ${ }^{18}$ This might be due to the fact that this was our initial experience, and these results may have been part of our learning curve. According to literature, the learning curve for total gastrectomy is 23 procedures. ${ }^{19}$ The current study included 11 patients, so an actual learning curve was not analyzed. Also, in our series, all patients were placed on a nil-by-mouth routine with enteral tube feeding by a needle-catheter jejunostomy the first 7 days postoperatively. Results may be further improved by implying a fast recovery protocol with early start on clear liquid diets and early mobilization. ${ }^{20}$

A D1 lymph node dissection was performed in this cohort of patients according to the international guidelines. ${ }^{21} \mathrm{We}$ found that the laparoscopic procedure yielded a median of 10 lymph nodes. All dissected lymph nodes were negative 
Fig. 6 Swiss roll with signet cell in HE staining (a, b), CAM5.2 staining (c), and E-cadherin immunohistochemistry (d)

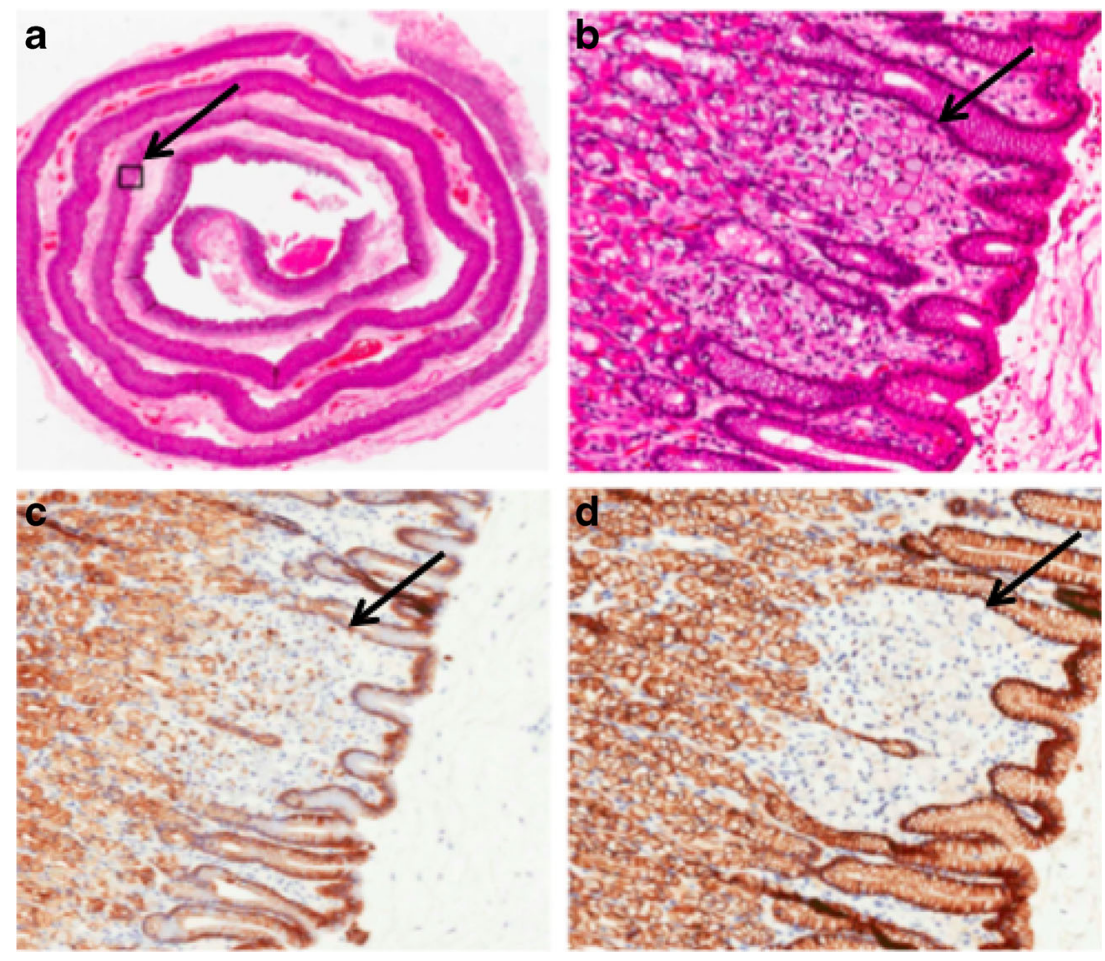

for metastases. This is in accordance with literature describing the removal of 10-12 lymph nodes, none of which contained metastases. ${ }^{12}$ Until now, after a median follow-up time of 28 (9-110)months, no recurrent disease or distant metastases were observed in our cohort, suggesting that a limited lymph node dissection is the appropriate procedure for these patients.

Compared to open total gastrectomy for gastric cancer, laparoscopic total gastrectomy showed less blood loss, fewer postoperative complications, and shorter hospital admission time as well in this series as in literature. ${ }^{13}$ Most probably, this is the result of less surgical trauma. The severity of surgical trauma can be assessed by measuring the serum levels of the acute-phase response cytokine IL-6. A recent systematic review indicated that an open procedure is associated with a higher inflammatory response, as is measured by IL-6 levels compared to a laparoscopic procedure. ${ }^{22}$ Unlike laparoscopic distal gastrectomy, laparoscopic total gastrectomy is still not widely accepted as first choice of treatment. This is probably a reflection of laparoscopic total gastrectomy being a technically more demanding procedure than laparoscopic distal gastrectomy with a long learning curve. ${ }^{23}$

\section{Conclusion}

In conclusion, we showed that prophylactic laparoscopic total gastrectomy with jejunal pouch for patients with germline CDH1 mutation is feasible and safe. Laparoscopic total gastrectomy is associated with less intraoperative blood loss, fewer postoperative complications, and shorter hospital admission time in comparison to open total gastrectomy. These benefits may be especially relevant to patients with germline CDH1 mutation. We therefore recommend experienced surgeons to consider prophylactic laparoscopic total gastrectomy as first choice for these patients.

\section{Grant support Not applicable.}

Open Access This article is distributed under the terms of the Creative Commons Attribution 4.0 International License (http:// creativecommons.org/licenses/by/4.0/), which permits unrestricted use, distribution, and reproduction in any medium, provided you give appropriate credit to the original author(s) and the source, provide a link to the Creative Commons license, and indicate if changes were made.

\section{References}

1. Jemal A, Bray F, Center MM, Ferlay J, Ward E, Forman D. Global cancer statistics. CA Cancer J Clin 2011;61(2):69-90.

2. Kaurah P, MacMillan A, Boyd N, Senz J, De Luca A, Chun N, Suriano G, Zaor S, Van Manen L, Gilpin C, Nikkel S, ConnollyWilson M, Weissman S, Rubinstein WS, Sebold C, Greenstein R, Stroop J, Yim D, Panzini B, McKinnon W, Greenblatt M, Wirtzfeld D, Fontaine D, Coit D, Yoon S, Chung D, Lauwers G, Pizzuti A, Vaccaro C, Redal MA, Oliveira C, Tischkowitz M, Olschwang S, Gallinger S, Lynch H, Green J, Ford J, Pharoah P, Fernandez B, Huntsman D. Founder and recurrent CDH1 mutations in families with hereditary diffuse gastric cancer. JAMA 2007;297:2360 2372 . 
3. Pedrazzani C, Corso G, Marrelli D, Roviello F. E-cadherin and hereditary diffuse gastric cancer. Surgery 2007;142: 645-57

4. Guilford P, Hopkins J, Harraway J, McLeod M, McLeod N, Harawira P, Taite H, Scoular R, Miller A, Reeve AE. E-cadherin germline mutations in familial gastric cancer. Nature 1998;392: $402-5$.

5. De Bruin JH, Ligtenberg MJ, Nagengast FM, van Krieken JH. From gene to disease; E-cadherin and hereditary diffuse gastric cancer. Ned Tijdschr Geneeskd. 2003;147:2474-7. Review.

6. Guilford P, Humar B, Blair V. Hereditary diffuse gastric cancer: translation of $\mathrm{CDH} 1$ germline mutations into clinical practice. Gastric Cancer. 2010;13:1-10.

7. Pharoah PD, Guilford P, Caldas C, International Gastric Cancer Linkage Consortium. Incidence of gastric cancer and breast cancer in CDH1 (E-cadherin) mutation carriers from hereditary diffuse gastric cancer families. Gastroenterology. 2001;121:1348-1353.

8. Norton JA, Ham CM, Van Dam J, effrey RB, Longacre TA, Huntsman DG, Chun N, Kurian AW, Ford JM. CDH1 truncating mutations in the E-cadherin gene: an indication for total gastrectomy to treat hereditary diffuse gastric cancer. Ann Surg 2007; 245: 873- 879 .

9. Schrader KA, Masciari S, Boyd N, Wiyrick S, Kaurah P, Senz J, Burke W, Lynch HT, Garber JE, Huntsman DG. Hereditary diffuse gastric cancer: association with lobular breast cancer. Fam Cancer. 2008;7(1):73-82.

10. Hoogerbrugge N, Ligtenberg MJ, Nagengast FM, Bonenkamp JJ, van Krieken JH. Preventive resection of hereditary diffuse gastric cancer. Ned Tijdschr Geneeskd. 2006;150(44):2417-20. Review.

11. Kluijt I1, Sijmons RH, Hoogerbrugge N, Plukker JT, de Jong D, van Krieken JH, van Hillegersberg R, Ligtenberg M, Bleiker E, Cats A; Dutch Working Group on Hereditary Gastric Cancer. Familial gastric cancer: guidelines for diagnosis, treatment and periodic surveillance. Fam Cancer. 2012 Sep;11(3):363-9

12. Pandalai PK, Lauwers GY, Chung DC, Patel D, Yoon SS. Prophylactic total gastrectomy for individuals with germline CDH1 mutation. Surgery. 2011;149(3):347-55.

13. Haverkamp L, Weijs TJ, van der Sluis PC, van der Tweel I, Ruurda JP, van Hillegersberg R. Laparoscopic total gastrectomy versus open total gastrectomy for cancer: a systematic review and metaanalysis. Surg Endosc. 2013 May;27(5):1509-20.

14. Dindo D, Demartines N, Clavien PA. Classification of surgical complications: a new proposal with evaluation in a cohort of 6336 patients and results of a survey. Ann Surg 2004;240(2):20513.

15. Kluijt I, Siemerink EJ, Ausems MG, van Os TA, de Jong D, Simões-Correia J, van Krieken JH, Ligtenberg MJ, Figueiredo J, van Riel E, Sijmons RH, Plukker JT, van Hillegersberg R, Dekker E, Oliveira C, Cats A, Hoogerbrugge N; Dutch Working Group on Hereditary Gastric Cancer. CDH1-related hereditary diffuse gastric cancer syndrome: Clinical variations and implications for counseling. Int J Cancer. 2012 Jul 15;131(2):367-76.

16. Ziogas D, Roukos DH. CDH1 testing: can it predict the prophylactic or therapeutic nature of total gastrectomy in hereditary diffuse gastric cancer? Ann Surg Oncol. 2009;16:2678 -2681.

17. Charlton A, Blair V, Shaw D, Parry S, Guilford P, Martin IG. Hereditary diffuse gastric cancer: predominance of multiple foci of signet ring cell carcinoma in distal stomach and transitional zone. Gut. 2004;53:814-20

18. Hackenson D, Edelman DA, McGuire T, Weaver DW, Webber JD. Prophylactic laparoscopic gastrectomy for hereditary diffuse gastric cancer: a case series in a single family. JSLS. 2010;14(3):348-52.

19. Lee J, Ryu K, Lee J-H, et al. Learning Curve for Total Gastrectomy with D2 Lymph Node Dissection: Cumulative Sum Analysis for Qualified Surgery. Annals of Surgical Oncology. 2006; 13:11751181.

20. Mortensen K, Nilsson M, Slim K, Schäfer M, Mariette C, Braga M, Carli F, Demartines N, Griffin SM, Lassen K; Enhanced Recovery After Surgery (ERAS ${ }^{\circledR}$ ) Group. Consensus guidelines for enhanced recovery after gastrectomy: Enhanced Recovery After Surgery (ERAS $\left.{ }^{\circledR}\right)$ Society recommendations. Br J Surg. 2014 Sep;101(10):1209-29.

21. van der Post RS, Vogelaar IP, Carneiro F, Guilford P, Huntsman D, Hoogerbrugge N, Caldas C, Schreiber KE, Hardwick RH, Ausems MG, Bardram L, Benusiglio PR, Bisseling TM, Blair V, Bleiker E, Boussioutas A, Cats A, Coit D, DeGregorio L, Figueiredo J, Ford JM, Heijkoop E, Hermens R, Humar B, Kaurah P, Keller G, Lai J, Ligtenberg MJ, O'Donovan M, Oliveira C, Pinheiro H, Ragunath K, Rasenberg E, Richardson S, Roviello F, Schackert H, Seruca R, Taylor A, Ter Huurne A, Tischkowitz M, Joe ST, van Dijck B, van Grieken NC, van Hillegersberg R, van Sandick JW, Vehof R, van Krieken JH, Fitzgerald RC. Hereditary diffuse gastric cancer: updated clinical guidelines with an emphasis on germline $\mathrm{CDH} 1 \mathrm{mu}-$ tation carriers. J Med Genet. 2015 Jun;52(6):361-374.

22. Zhen-Bo Shu, Hai-Ping Cao, Yong-Chao Li, Li-Bo Sun. Influences of laparoscopic-assisted gastrectomy and open gastrectomy on serum interleukin-6 levels in patients with gastric cancer among Asian populations: a systematic review. BMC Gastroenterology 2015, 15: 52.

23. Kim MG, Kim KC, Yook JH, Kim BS, Kim TH, Kim BS. A practical way to overcome the learning period of laparoscopic gastrectomy for gastric cancer. Surg Endosc. 2011 Dec;25(12):3838-44. 